Article

\title{
Engineering Project: The Method to Solve Practical Problems for the Monitoring and Control of Driver-Less Electric Transport Vehicles in the Underground Mines
}

\author{
Shuai Li ${ }^{1}\left(\mathbb{D}\right.$, Guojun Wang ${ }^{1}$, Haoxuan $\mathrm{Yu}^{1,2, *,+}$ and Xinmin Wang ${ }^{1}$ \\ 1 School of Resources and Safety Engineering, Central South University, Changsha 410083, China; \\ shuaige@csu.edu.cn (S.L.); 8210183012@csu.edu.cn (G.W.); 15200826420@163.com (X.W.) \\ 2 Institute of Electrical and Electronics Engineers (IEEE), New York, NY 10001, USA \\ * Correspondence: yuhaoxuan@csu.edu.cn \\ $\dagger \quad$ The leader of the whole project.
}

Citation: Li, S.; Wang, G.; Yu, H.; Wang, $X$. Engineering Project: The Method to Solve Practical Problems for the Monitoring and Control of Driver-Less Electric Transport Vehicles in the Underground Mines. World Electr. Veh. J. 2021, 12, 64 . https://doi.org/10.3390/wevj12020064

Academic Editor: Joeri Van Mierlo

Received: 22 March 2021

Accepted: 21 April 2021

Published: 23 April 2021

Publisher's Note: MDPI stays neutral with regard to jurisdictional claims in published maps and institutional affiliations.

Copyright: (c) 2021 by the authors. Licensee MDPI, Basel, Switzerland. This article is an open access article distributed under the terms and conditions of the Creative Commons Attribution (CC BY) license (https:// creativecommons.org/licenses/by/ $4.0 /)$.

\begin{abstract}
With the continuous development of Artificial Intelligence technology and Internet of Things engineering, more and more driver-less vehicles have been developed and put into industrial production. The birth of driver-less vehicles undoubtedly brings new vitality to a large amount of industries, particularly in transportation. For the mining industry, transportation is undoubtedly an extremely important link in the whole production process. If the driver-less vehicles can be applied to the underground mines, it can not only improve the production and transportation capacity of the whole mine but also can reduce the occurrence of many mine safety accidents. ZigBee WSN technology can play a greater role in the narrow environment such as underground mines according to the relevant literature; this concept paper, similar to an engineering project plan, mainly tries to integrate the ZigBee WSN technology and the communication-based train control (CBTC) system to explore the possibility of the driver-less vehicles to be used in the underground mines, which aims to solve practical engineering problems for the engineering projects. As the mining engineers, we put forward the concept of this integrated system in this concept paper, but we need to continue to work hard for the future of the underground mines. This concept paper serves as a guide to Tossing out a brick to get a jade gem, and it has a few implications for the development of underground mine transportation.
\end{abstract}

Keywords: driverless transport vehicle; ZigBee WSN technology; communication-based train control (CBTC) system; underground transportation; mining engineering; concept

\section{Introduction and Background \\ 1.1. Retrospective: The Development of Driver-Less Technology}

With the continuous development of the science and technology, researchers all over the world have begun to devote themselves to the "Revolution" of the Artificial Intelligence technology and Internet of Things engineering, and to contribute to the development of various industries. However, the driver-less technology of vehicles is also the product of this "Revolution". With the comprehensive promotion of Artificial Intelligence technology, the driver-less technology presents a rapid development trend. There is no doubt that the driver-less technology has become the latest development direction of vehicle industry all over the world. Compared with traditional cars, self-driving cars can effectively improve the safety, traffic efficiency, and comfort of vehicles.

In a 2003 report of Cheon [1], Cheon noted that as early as 1939, the United States firstly exhibited the concept design of the driver-less technology at the New York World Expo. He thought although the design was simple, it was a sensation to some extent at the time. The world's first driver-less vehicle was developed by the Carnegie Mellon University in 1984. This remarkable academic achievement made a really great sensation 
in the world, and even years later, researchers still reported on how the driver-less vehicle worked one after another. In 1987, three years after the birth of the driver-less technology, Goto and Stentz [2] published their core research on the CMU system, which is derived from Carnegie Mellon University.

As the research mentioned above, the early driver-less vehicles used CMU systems, a system based on Artificial Intelligence computing, and Computer Control, which was studied by many researchers from the 20th century to the early 21st century.

In 1987, Goto and Stentz [2,3] tried to apply the CMU system to the intelligent control of robots. In 1988, Parker et al. [4] studied the functions of automatic control of the CMU system through practice, and they suggested that the CMU system can be further optimized. In 1989, Stouffer [5] reported that Carnegie Mellon University, the founder of the CMU system, had been doing the research on developing a new system based on the advantages and disadvantages that the CMU system had shown before; the same year, Carley et al. [6] proposed some improvements to the simulation of the CMU system.

After entering the 21st century, it is obvious that more and more control systems appear, which provides favorable logistic support for the driver-less technology. Specially, a researcher [7] proposed the use of laser sensors to guide driver-less vehicles forward in 2005, and Zhang et al. [8] built a new simulation platform for driver-less vehicles, which can evaluate the performance of driver-less vehicles more accurately.

As a pioneer in the introduction of the driver-less vehicle road testing, Google officially launched the driver-less vehicle project in 2009 [9]. Uber also launched the driver-less vehicle travel project in 2016 [10], and in the same year, under the pressure of competition from peers, Google split the driver-less business and set up Waymo Company to accelerate the commercialization of driver-less vehicles [11]. Developing countries have also made significant breakthroughs in the area of driver-less vehicles in recent years; in August 2018, a driver-less minibus developed jointly by Baidu and Jinlong Bus of China achieved small-scale mass production [12].

At this stage, driver-less technology seems to be more used in people's daily travel; Google, Uber, and so on are committed to the application of driver-less technology in people's daily driving.

\subsection{Retrospective: Literature Recommendations for the Readers}

- On people's expectations about the driver-less technology, the concept paper recommends the relevant literature $[13,14]$ :

Firstly, Legacy et al. [13] believed that audio and video (AV) technology has the potential to change the urban landscape and existing transportation systems and networks, so in the literature, they revealed conceptual gaps, prospects, and limitations of their ideas in the framework of audio and video (AV) technology. The video [14] in 2015 demonstrated the role of driver-less technology in energy consumption and environmental protection, and it proposed a vision for future driver-less technology.

- On application of the driver-less technology in engineering, the concept paper recommends the relevant literature [15-18]:

In 2019, Robots [15] based on driver-less technology overcame the engineering challenges of safety, and the news report "DRIVERLESS" [16] also played an important role to describe the development of driver-less technology, as well as the news report "Driverless car coming" [17] and "Driverless CARRIAGES" [18] to describe the applications of driver-less technology in the engineering.

- On the meaning of the driver-less technology in people's daily life, the concept paper recommends the relevant literature [19-23]:

In 2019, Salonen and Haavisto [19] summed up the feelings of passengers on the driver-less bus in Finland to describe the perception of taking a driver-less car. As early as in 2017, some researchers [20] have carried out research on driver-less technology to 
improve the travel and life quality of people with disabilities, which is of great significance to the disabled.

In 2018, Blau, Akar and Nasar [21] started the research about the influence of the driver-less technology on the drivers in non-motorized lanes, especially the bike riders. It is an interesting work. In 2020, Allan [22] reported on the development of driver-less technology in the UK, and Bissell et al. [23] explored the impact of driver-less technology on society.

- On the future of the driver-less technology from other perspectives, the concept paper recommends the relevant literature [24-26]:

Sanguinetti [24] and Talley [25] considered the future of driver-less technology from a perspective of the law, and Forlano [26] considered the future of driver-less technology from a perspective of the business and urbanization.

- On the recent technologies applied in the driver-less vehicles, the concept paper recommends the relevant literature [27,28]:

Wu et al. [27] used Bayesian Network modeling for safety management of electric vehicles transported in RoPax ships, and this research is of great significance to driver-less technology. Meanwhile, on the 12th International Joint Conference on Computational Intelligence, Emanuele Ferrandino et al. [28] proposed a combination of public-transport electric vehicles and smart grids, that is, nanogrids.

\subsection{Retrospective: Driver-Less Technology in the Industrial Transportation}

Since the late 20th century, driver-less technology has been increasingly used in industrial transport.

However, as early as in 1998, Bordelon Hoff and Sarker [29] designed and applied automatic guidance vehicles (AGV) to industrial transportation based on driver-less technology; in 2001, applying driver-less technology to industrial transport, Barshick and Helms [30] described the process by which Alcoa USA implemented and used automatic guidance vehicles (AGV) to improve its production process. In 2011, Bellamy and Pravica [31] assessed the significance of introducing driver-less technology into the industrial transportation of an Australian open pit, and in 2014, Bartley [32] had also proposed the use of driver-less technology in the trucking industry.

After 2015, driver-less technology has begun to develop rapidly, especially in industrial transport. In 2016, Ohashi et al. [33] solved the problem of using a group of small mobile robots based on the driver-less technology to transport large weights, and the robots they developed could use wheelbarrows for transport operations, which are ideal for use in industrial plants and other places. In fact, Sakuyama et al. [34] proposed the robotic transportation based on driver-less technology in 2014, so that later researchers continued to optimize it. In addition to the robots, the advent of driver-less forklifts has also contributed to transport efficiency in factories and warehouses, in 2019, Brown [35] introduced the principles of driver-less forklifts used in industrial transport in recent years.

From 2015 to now, there is also an increasing number of ideas and practices on driverless technology that are realized in industrial transportation. It is reported [36] that in 2017, driver-less trucks were being used to transport parts and components between factories, and in 2018, Hjalmarsson-Jordanius et al. [37] developed and applied the driver-less technology for logistics transportation.

\subsection{Retrospective: Driver-Less Technology in the Underground Transportation}

With the continuous progress of industrial development, Artificial Intelligence technology and Internet of things technology are widely used in various industries. Therefore, driver-less technology has been gradually applied in industrial transportation; of course, the mining industry is no exception. With the rapid development of mining science and technology in the world, many underground mines have gradually entered the stage of intelligence. However, underground mines face many challenges in the process of intelligent 
development, such as underground transportation. In the past 20 years, many researchers have devoted themselves to the research of intelligent underground mines, including the research of intelligent underground mine transportation, especially the driver-less transport vehicle.

In fact, driver-less technology began to be used in underground mines around 2015. In 2011, Benter, Antolovich and Moore [38] were the first to argue that the mining process is moving in the direction of driver-less on the 2011 6th International Workshop on Advanced Ground Penetrating Radar (IWAGPR) Conference. In the same year, Meech and Parreira [39] begun to explore the possibility of driver-less applications in mines and developed the simulation models. In the year 2013, Korane [40] thought driver-less vehicles may signal the future of the mining industry: the intelligent mining. In 2015, Murden [41] from Australia reported on the effectiveness of driver-less trucks operating in Australian mines. In 2016, a researcher [42] mentioned that the scheduling of vehicles in underground mines was a very important thing, but if the intelligent control of vehicles could be realized, a lot of cost and time was able to be saved. In the same year, Shiers and Barnett [43] from the US experimented with driver-less trucks; the results were undoubtedly successful, and many researchers who studied mining also applied driver-less trucks in underground mines based on their successful experience.

In recent years, driver-less technology in underground mines has been further optimized and developed. Cheng [44] proposed to apply an SINS/DGPS integrated navigation system to the navigation of driver-less vehicles in underground mines in the year 2019, and Doran and Lopez [45] believed that the application of driver-less technology to underground mines is definitely the way to ensure mine safety. In 2020, Dong et al. [46] suggested that underground mines be used as a pilot to promote driver-less vehicles; they thought that the popularization and application of driver-less vehicles in underground mines can solve the problem of deep mining, reduce the frequent disasters under bad conditions, and protect the life and property safety of miners as well as provide technical support for the safe and efficient recovery of deep resources.

It can be inferred that to apply driver-less vehicles to the underground mines, the researchers on the research of mining engineering must make unremitting efforts.

\section{Idea and Design}

The purpose of this concept paper, similar to an engineering project plan, is to conceptualize an integrated system for the monitoring and control of driver-less vehicles for the practical problems in underground mines:

In 2015, Dash et al. [47] raised the opinion that there were two practical engineering problems in the engineering projects that need to be solved urgently for underground mines driver-less electric transport vehicle: (1). Vehicle Safety Problems such as vehicle rollover and the rear-end collision and (2). Vehicle Scheduling Problems such as vehicle movement during transport operations.

Therefore, the integrated system is required to be designed with the monitoring and control functions; also, for developing countries such as China, the cost of the integrated system is important as well.

\subsection{The Comparison of ZigBee WSN Technology and Other Technologies}

5G technology is the first technology that we thought of for the monitoring and control of underground mining vehicles, and in fact, $5 \mathrm{G}$ technology has been used by researchers and companies in communications for underground mines. In 2019, Ghaddar et al. [48] have used $5 \mathrm{G}$ technology to do some communication simulation tests in underground mines, and in 2020, Chinese researcher Ma [49] summarized the construction significance of intelligent mine construction and intelligent mine structure and then introduced in detail the application of 5G wireless communication system in intelligent mines; from then on, more and more Chinese researchers began to study the application of 5G technology in underground mines. It can be said that $5 \mathrm{G}$ technology is the most sophisticated commu- 
nication technology currently; however, at this stage, the 5G technology is obviously not perfect. For example, its functional area coverage is small and the cost is high. For developing countries such as China, 5G technology has not been widely applied on the ground communication, it is even less likely to be widely used underground at this stage. So, we do not consider using 5G technology in the monitoring and control of the underground mines because of the limitations mentioned above. Similarly, although Radar Sensor [50,51] has also been successfully used in the safety monitoring and location in the underground mines in recent years, its limitations are the same as 5G technology — that is, high-cost and non-universal.

The electric vehicles running in the underground mines are shown in Figure 1.

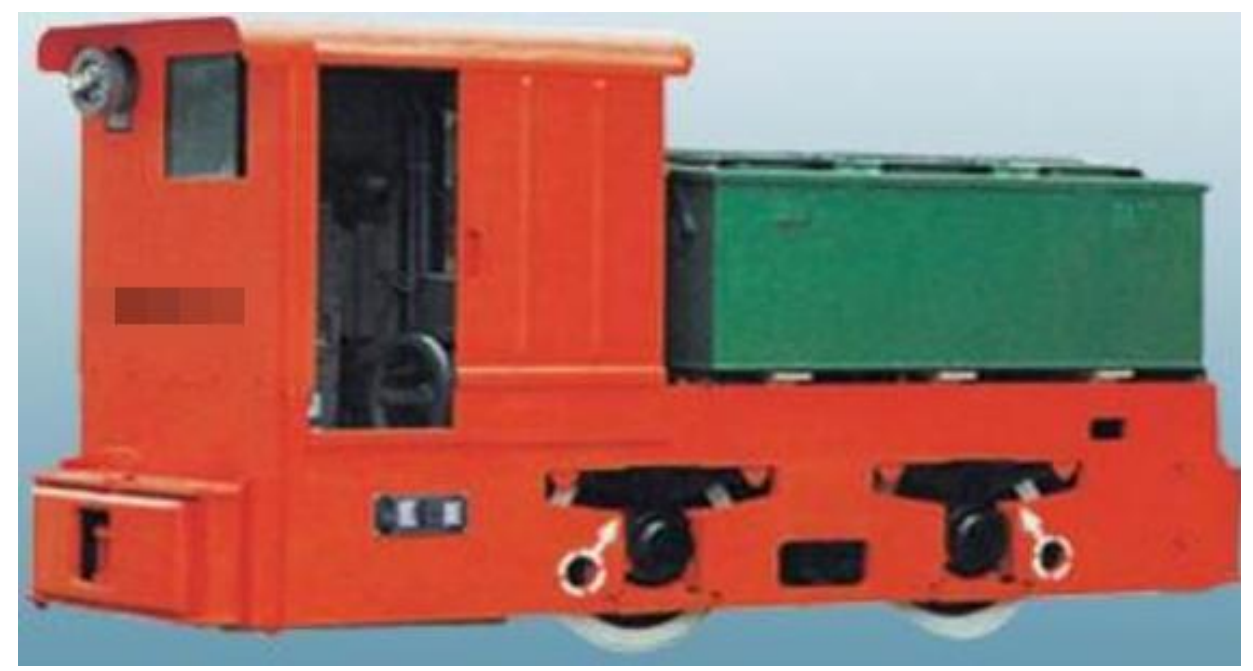

Figure 1. The electric vehicle in the underground mine.

A Wi-Fi Communication System has also always been used in underground mines; Ikeda et al. [52] tested and verified the application of a Wi-Fi Communication System in an underground mine environment in 2019, and recently, Min and Jinhao [53] announced their progress in applying the Wi-Fi 6 technology to underground mines and achieved good results. As a flexible and convenient wireless communication technology, Wi-Fi technology is worth being widely used in mines, but at the same time, the consumption and operating costs of Wi-Fi technology in underground operation are also unaffordable for the small and medium-sized mines, especially in developing countries such as China.

Generally speaking, ZigBee WSN technology is functionally similar to Wi-Fi technology and the energy consumption and operating costs of ZigBee WSN technology are lower. Meanwhile, in the research of Moridi et al. [54,55], ZigBee WSN technology is often considered an economical, efficient, and applicable option compared to other WSN in underground mines. ZigBee WSN technology, they argued, could improve the workplace health and safety for workers, cost-effectiveness, management of technical issues, energy conservation, and real-time response to events. Therefore, ZigBee WSN technology is more suitable for the underground mines in the monitoring and control.

ZigBee technology was born around 2007; Business Wire [56] reported the birth of ZigBee technology.

The ZigBee WSN technology based on IEEE 802.15.4 protocol is a new kind of wireless sensor technology, which has more advantages than other wireless sensor networks in underground monitoring and communication systems. Even if ZigBee WSN technology only provides a low data rate, it also has benefits- that is, low power consumption, low cost, convenient network installation, and maintenance.

Since 2012, Chen, Yao and $\mathrm{Wu}$ [57] theoretically analyzed the power consumption of ZigBee MAC using different modulations; they proposed that low power consumption is the biggest feature of ZigBee WSN technology, and they believed that optimizing ZigBee 
WSN technology will bring benefits to all walks of life. In 2017, Uradzinski et al. [58] found the positioning function of ZigBee WSN technology excellent; as a result, some researchers believed that ZigBee technology in the underground mine environment could play its specialty. Specially, Moridi et al. [54,55] did two studies in 2014 and 2018, reporting comparisons between ZigBee WSN technology and other underground communication networks, and they concluded that ZigBee WSN technology has more advantages. Moridi et al. [54,55] indicated that the narrow space of underground environment significantly enhances the signal intensity; as a result, ZigBee WSN technology can play a great advantage in the underground environment. As well, Moridi et al. [59] studied the ZigBee applications of developing ZigBee nodes in underground monitoring and communication in the field of safety and health in practical cases to improve network performance.

In fact, as early as in 2008, the year after ZigBee WSN technology emerged, Limin et al. [60] applied ZigBee technology to underground mine safety monitoring systems; they used the ZigBee WSN technology to collect temperatures, humidity, and methane from underground coal mines, and then, ZigBee WSN technology transfers data to ARM-based information processing terminals. In the same year, 2008, Hongjiang and Shuangyou [61] achieved real-time monitoring and alarm of the underground environment and production parameters by the communication function of the ZigBee WSN technology. In the year 2009, Pei et al. [62] put forward the superiority of ZigBee WSN technology in underground mines because of the narrow environment of the underground mines, as narrow space could enhance the signal intensity of ZigBee WSN technology.

Since 2010, ZigBee WSN technology has been widely used in underground mines, especially in the safety and environment monitoring. Chehri et al. [63] suggested that mining automation might be possible through ZigBee WSN technology, Bian [64] proposed that ZigBee technology is to some extent an auxiliary tool for collecting information, and his view was recognized by most researchers. Interestingly, Li, Zhao, and Liu [65] designed a high-performance wireless robot network communication system for underground mines based on ZigBee WSN technology.

ZigBee WSN technology was first used in the location of underground mine personnel and then gradually used in the monitoring of transport equipment. Around 2015, Jiang et al. [66-69] researched of the location of underground miners based on ZigBee WSN technology; Ge et al. [70] mentioned that the use of traditional positioning methods would have a large error in the location of underground vehicles. Therefore, he proposed an improved received signal strength indication (RSSI) positioning algorithm, and from then on, later generations began to try to apply ZigBee WSN technology to vehicle positioning in underground mines.

In general, ZigBee WSN technology is also often used as a medium for monitoring data transmission, which seems to have gradually become an academic consensus [71-73].

\subsection{The Comparison of Communication-Based Train Control (CBTC) System and Other Technologies}

Nowadays, the communication-based train control (CBTC) system is commonly used in the urban rail transit system all over the world, and the CBTC systems currently operating worldwide are the "products" of advances in Internet of Things and Artificial Intelligence.

In the CBTC system, the three subsystems that have outstanding performance in monitoring and control are the ATO (Automatic Train Operation) system, the ATP (Automatic Train Protection) system, and the ATS (Automatic Train Supervision) system. The ATO system is the Automatic Train Operation system; similar to the ZigBee WSN technology, the ATO system is also always used as a medium for monitoring and controlling data transmission. The distance and speed information of the transport vehicles are collected by the ATO system and transmitted to the ATP (Automatic Train Protection) system, which is the control system of the CBTC system. The ATS system is the Automatic Train Supervision system, which is the monitoring system of the CBTC system. Zhu et al. [74] did the research on the anti-interference ability of the CBTC system to optimize the Supervision Function of the ATS system in 2020, and in 2013, Wang et al. [75] raised the importance of the overall 
coordination of the CBTC system; only through the combined operation of these systems can the functions of safety protection, automatic driving, driver's communication, and interaction be realized.

Although the current CBTC system is considered to be able to detect and monitor the operation of transport equipment over rail, in an environment such as underground mines, the running range of trackless transport equipment is defined by the driveway, so the CBTC system is also able to monitor driver-less vehicles in an environment such as underground mines. Through summarizing the successful application of the CBTC system in the Las Vegas monorail tram [76], some researchers put forward the application of the CBTC system in underground driver-less vehicle monitoring. Although CBTC systems are generally used for railway traffic monitoring, they believed that the running environment of vehicles in the underground mines is restricted to the transport lanes, which is not as wide as the ground traffic environment, similar to monorail trams. In fact, as early as 2006, Bin et al. [77] proposed creating an underground city by the CBTC system. In 2013, Wang et al. [78,79] published their research on the underground simulation of CBTC system, and in 2014, Briginshaw [80] explored whether the CBTC system could be used in underground vehicles in London. Although the running environment of underground mine transportation is similar to that of the subway, the running of the subway is mainly for the service of passengers, similar to Urban Rail Transit. Therefore, as the CBTC system can be used in the running of underground subway to some extent, with the precedent, it is believed that it is possible for the CBTC system to be used in the underground mines.

Guo, Du, and $\mathrm{Xu}$ [81] solved the problem of underground coal mine vehicle positioning based on an IMU inertial navigation system, and they combined an NAV2 inertial navigation unit and PNP photoelectric speed sensing to realize real-time interaction with upper monitor through wireless network. According to their report on the 2018 International Conference on Robots and Intelligent System (ICRIS), it seemed that the IMU inertial navigation system performed well in locating vehicles in underground coal mines, especially in terms of positioning accuracy. As for other technologies used in the control and monitoring of the vehicle, Czaplewski et al. [82] established the tracking equations for the monitoring and control of the railway transportation through the Global Navigation Satellite System (GNSS) and Geodetic Networks (GN) in 2020, and Chen et al. [83] established the tracking equations by $5 \mathrm{G}$ technology. For these technologies, although their emergence shows the progress of modern science and technology and promotes the development of vehicle monitoring system, it is obviously difficult to absolutely realize these technologies in practical engineering. Compared with these systems, the CBTC system is obviously a more developed technology at this stage, and the vehicle monitoring of the CBTC system in a fixed lane such as an underground mine environment is more convenient and has lower consumption than other systems with wireless transmission, but whatever control and monitoring systems will emerge in the future, as long as these systems can be applied to specific practical problems and engineering projects to achieve good results, the efforts of researchers around the world who are on the research of the innovative system will not be in vain.

\subsection{Idea: System Integration}

Achieving the remote control of driver-less electric transport vehicles in underground mines requires the combination of the monitoring and control function of the CBTC system and the information transmission function of ZigBee WSN; therefore, this concept paper mainly tries to integrate the ZigBee WSN and the communication-based train control (CBTC) system to explore the essential functions of driver-less vehicles specially used in underground mines, which aims to solve practical engineering problems.

As is known, ZigBee WSN can play a better role in the narrow environment such as underground mines, especially since its short-distance communication and low power consumption characteristics can be fully applied. 
Recently, ZigBee WSN have been widely used in the environment monitoring of the underground mines. In 2020, Jia et al. [84] put forward that ZigBee WSN gets information through various sensors in the underground mine and transmits the information to the station; Dorthi, Bayyapu and Karra [85] divided the mine into areas and independently monitored each area through the ZigBee WSN. In 2021, Yang et al. [86] improved the communication function of ZigBee WSN based on the background of a mine. Although Celaya-Echarri et al. [87] also proposed several other monitoring methods for the underground environment, there is no doubt that ZigBee WSN have greater superiority in information transmission of the underground environment.

As an effective train control system, the CBTC system is also remarkable in the underground environment. For above-ground transportation, Blanco, García and Morenas et al. $[88,89]$ all agreed that the CBTC system required to be used in conjunction with wide-area sensing networks such as Wireless Sensor and Actuator Network (WSAN), but it is different in the underground mines because of the narrow environment of the underground mines. Therefore, to realize the monitoring and control of underground driver-less electric transport vehicles and the underground environment, it is a good choice to combine ZigBee WSN with the CBTC system. In 2018, Zhang [90] proposed that the CBTC system needs three parts of functional support for the control of transportation equipment; that is, an information transmission function, monitoring function, and control function. According to the idea of Zhang [90], the integrated system is established below.

To realize the monitoring and control function for driver-less electric transport vehicles, the integrated system is composed of three parts:

1. The information transmission function from the ATO system and ZigBee WSN.

2. The control function from the ATP system.

3. The monitoring function from the ATS system.

The ATO system collects the speed and distance information of each driver-less electric transport vehicle, ZigBee WSN collect the initial location information of each driver-less electric transport vehicle and the temperature, humidity, concentration of harmful gases in the underground environment; these information about the underground environment can also serve as a reminder and reference for the whole project. When all the information is collected, it is transmitted to both the ATP and the ATS system by the ATO system and the ZigBee WSN. When the information arrives at the ATS system, the information will be fed back to the monitoring screen of the ATS system. When the information arrives at the ATP system, the ATP system will control each driver-less electric transport vehicle properly according to the information provided; meanwhile, the content of the control operation will be also fed back to the monitoring screen of the ATS system. When the initial location information of each driver-less electric transport vehicle arrives at the ATS system, the ATS system will continue to track the location of the vehicle through known information and feed back to the screen.

As mentioned above, for the ZigBee WSN, we considered trying to locate the initial position of each static vehicle and monitor the temperature, humidity, and concentration of harmful gases in the underground environment by the function of the ZigBee WSN. In our previous study, we tried to use sensors to identify and locate the initial position of the vehicle, but the effect was not good, so we planned to use ZigBee WSN to improve the positioning and testing of the initial position of the vehicles in the underground mines, and the location tracking of the running vehicles depends on the ATP system and ATS system in the CBTC system; we even established the tracking equations for the ATS system in our previous research, and here, we briefly introduce the tracking equations we have established:

In Equations (1) and (2) shown below, $m$ represents the line mileage of the transport vehicle, $S_{b}$ represents the blocked area, $Y_{\beta}$ represents the mileage from $m$ to the axle counting area end, $L_{u}$ represents the length of the transport vehicle, $L_{u-a}$ represents the 
transport vehicle position's uncertainty amount, and $V_{\max }$ represents the transport vehicle's maximum allowable operating speed.

$$
\begin{gathered}
T_{\text {hesway of mine }(m)}=\frac{S_{b}+L_{u}+L_{u-a}}{V_{\max }} \\
S_{b}=Y_{\beta}-m
\end{gathered}
$$

Equations. Tracking equations.

Therefore, the concept design of the integrated system is as explain below:

- The ATO system of the CBTC system collects the speed and distance information and sends it to the ATP system.

- The ATP system of the CBTC system controls each vehicle in the underground mine according to the information provided by the ATO system.

- The ZigBee WSN collects the initial position of each static vehicle and monitors the temperature, humidity, and concentration of harmful gases in the underground environment.

- The information of the speed, distance, temperature, humidity, and concentration of harmful gases will be fed back to the screen of the ATS system, and the running process of the vehicles will be also fed back to the screen.

It is worth mentioning, in our concept design, the aim of collecting the initial position of each static vehicle is to ease the burden of the ATS system in vehicle monitoring and tracking, and the main control system of the integrated system is the ATP system. The concept design of the integrated system is shown as below Figure 2 .

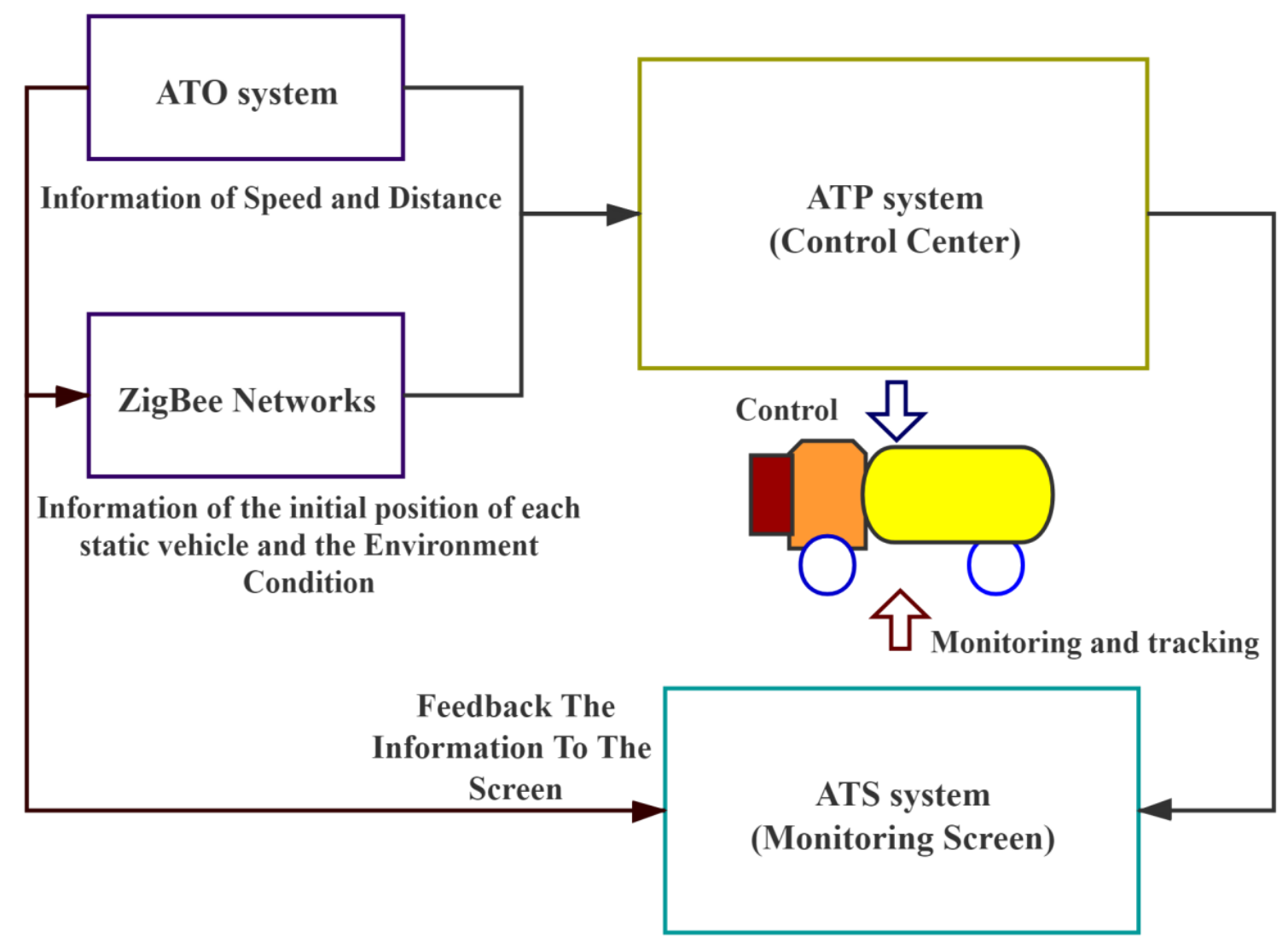

Figure 2. Concept design of the integrated system. 


\section{Concept: The Methods to Solve the Practical Problems in the Mining Engineering Projects}

\subsection{Vehicle Safety Problems}

The ATP system is the core system to control vehicle speed and vehicle safety distance before and after. The ATP system controls and regulates the minimum interval and over-speed protection in vehicle operation to avoid rear-ending any vehicles. The main components of the ATP system include range measuring equipment, speed monitoring equipment, vehicle-ground interaction equipment, and emergency braking equipment. To control the hidden danger of vehicle safety, it is also necessary to ZigBee WSN and the ATO system as the medium of information transmission. The real-time running state of each vehicle is fed back to the monitoring screen of the ATS system.

On the premise of solving the problem, a method is needed to judge whether the problem appears or not. In previous studies, the control of underground mine transport vehicles is generally driven by manual driving; even driver-less vehicles will only be realized through some short-distance communication emergency control. At the 2020 IEEE 23rd International Conference on Intelligent Transportation Systems (ITSC), Gao et al. [91] published research on the safety function of the ATP system and proposed a new analysis method for the ATP system, the Dynamic Fault Tree analysis method. The Dynamic Fault Tree is a method system to evaluate the reliability and security of a complex system, and it is also a deductive method based on fault event. It is analyzed step by step according to top-down order through certain logical reasoning steps until the result is obtained. The Dynamic Fault Tree analysis method is to model the fault logic according to the dynamic fault behavior, which accords with the function design of the signal system. It is worth mentioning that logical analysis based on the Dynamic Fault Tree analysis method usually analyzes the emergence of problems at the same time, rather than layer-by-layer analysis, which can greatly improve the efficiency of problem solving. The order of problem solving based on the Dynamic Fault Tree analysis method proposed by Gao et al. [91] is as follows: (1). Identify the possible fault events. (2). According to the possible fault events, establish the analysis process of them. (3). Through the control system, analyze whether the fault events occur. (4). If the fault events occur, solve them through the control system.

Through the analysis of the information transmitted by the ATO system and the ZigBee WSN, the ATP system begins to analyze whether the problem appears, and the analysis process of the fault events based on the Dynamic Fault Tree analysis method has been established: (1). According to the speed and the distance information provided by the ATO system, if the distance between the vehicles may cause an accident, the distance would be controlled by the control function of the ATP system through controlling the speed of the vehicles. (2). If the rollover accidents appear, the control function of the ATP system will halt the nearby vehicles in the underground mine. (3). If the emergency appears, the control function of the ATP system will halt all the vehicles in the underground mine. (4). The information of the initial location and the environment condition collected by the ZigBee WSN plays an important role in the tracking and monitoring of the underground vehicles and the rescue of personnel in the rollover accidents or the emergence. (5). The whole process will be fed back to the screen of the ATS system.

With the improvements based on the Dynamic Fault Tree analysis method proposed by Gao et al. [91], the process logic diagram of the ATO system, ZigBee WSN, and the ATP system to solve the safety problems is shown in Figure 3.

\subsection{Vehicle Scheduling Problems}

In the transportation operation, it is inevitable to encounter the problems of scheduling, such as the control of departure time and the choice of transportation route of transport vehicles; therefore, the importance of information transmission is particularly important at this moment. Terblanche and Bley [92] put forward their opinion optimizing the scheduling of underground vehicles, which is able to greatly improve the production and transportation efficiency of underground mines. As well, Astrand et al. [93] regarded the underground 
mine transportation system as a production workshop, and if the "Production Line" is well scheduled, it will significantly improve efficiency. In fact, as early as in 2005, Gamache, Grimard and Cohen [94] had proposed a shortest-path algorithm for the scheduling problems, and from then on, many researchers such as O'Sullivan et al. [95,96] began to do the research to optimize the shortest-path algorithm for the scheduling problems. In 2019, Yardimci and Karpuz [97] proposed adding Artificial Intelligence Computing capabilities into the shortest-path algorithm for the scheduling problems in the underground mines, which has become the direction of the efforts of later researchers.

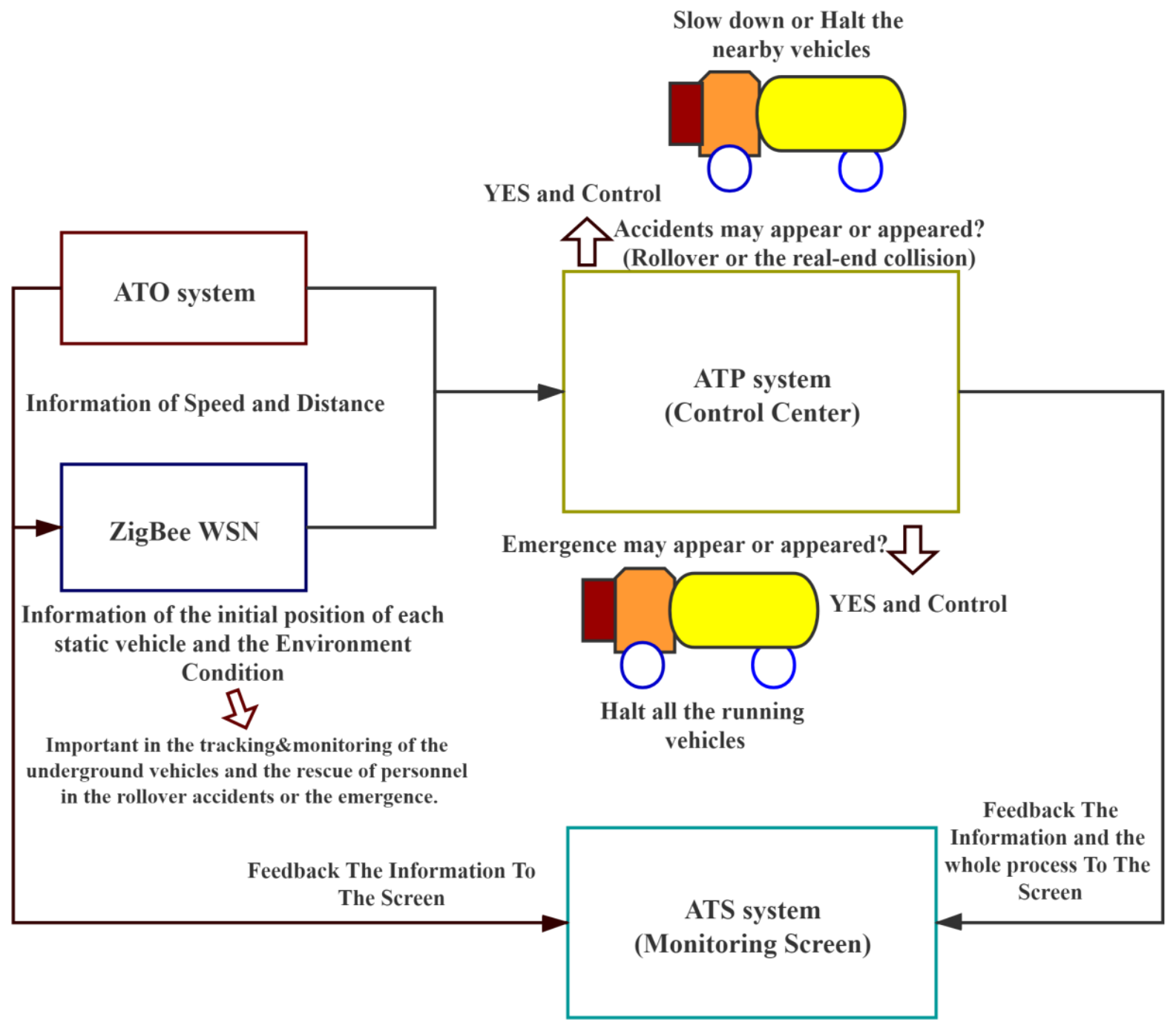

Figure 3. The process logic diagram of the solution to the safety problems.

Before the emergence of Artificial Intelligence, the scheduling of underground vehicles was done manually, but after the AI has appeared, researchers [98-100] proposed an analysis process based on the AI computing applying in the scheduling with the guidance of the CBTC system and ZigBee WSN; once there is a Stope that needs transport operations, the process begins running: (1). The ATS system and AI Computing analyze the congestion of each transportation route. (2). When ATP system gets the feedback from the AI Computing, it will automatically choose the best route for the vehicles to participate in the transport operations or the unloading places to participate in the unload operations. (3). The information of the initial location and the environment condition collected by the ZigBee WSN plays an important role in the tracking and monitoring of the underground vehicles and the rescue of personnel in the rollover accidents or the emergence. (4). The whole process will be fed back to the screen of the ATS system. 
With the improvements based on the shortest-path algorithm and AI computing proposed by researchers [92-100], the process logic diagram of the ATO system, ZigBee WSN, and the ATP system to solve the safety problems is shown in Figure 4.

When transport operations are required.

Choose the best route to the Stope

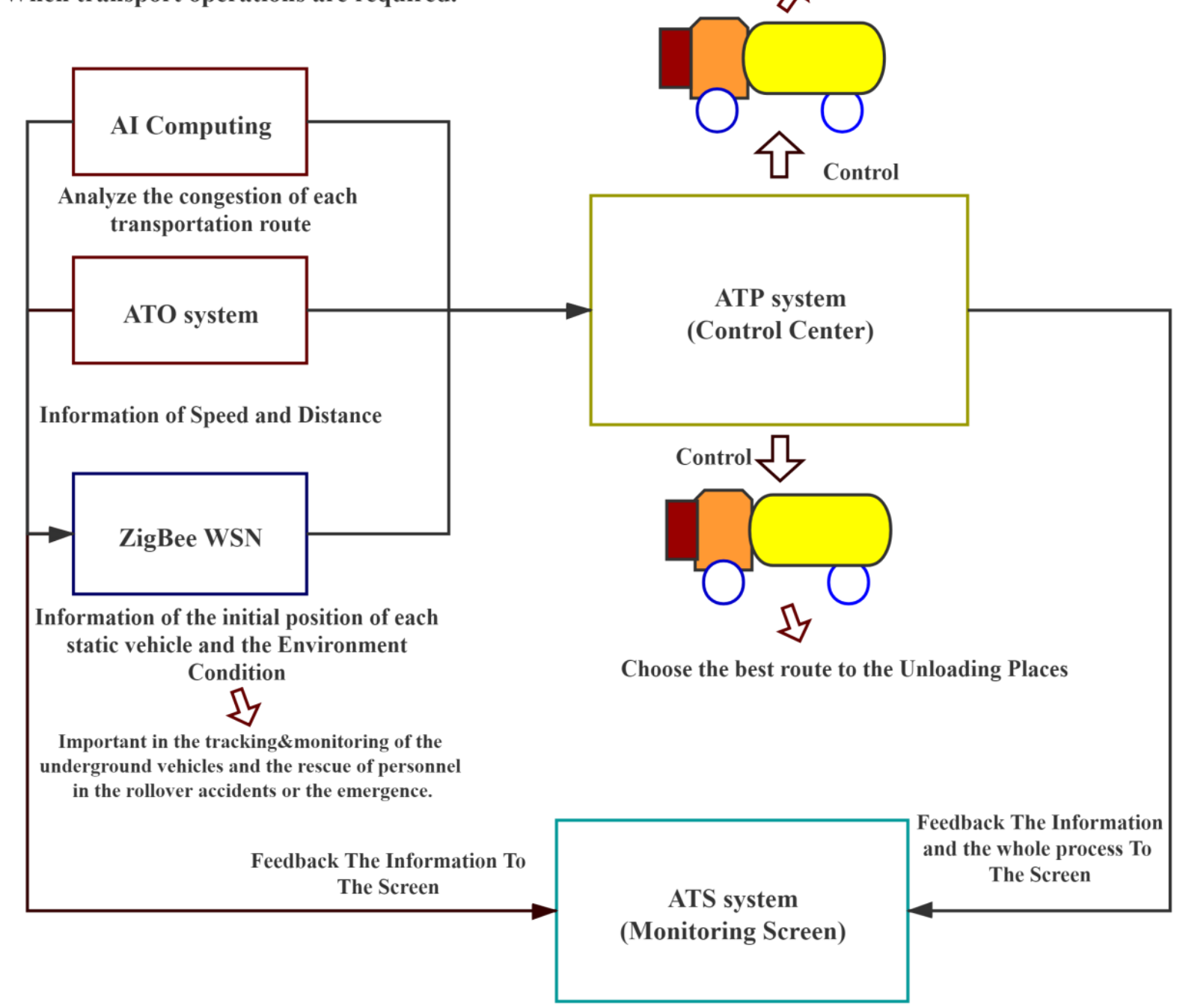

Figure 4. The process logic diagram of the solution to the scheduling problems.

\section{The Work for the Next Step}

Although the concept paper does a great deal of work in the design of the integrated system that aims to solve the practical problems in the engineering projects, there are still a lot of weak points: (1). Since we are the engineers doing the engineering projects, focusing on the application of advanced technology in engineering, in this design, we only proposed the concept of the integrated system; the topology of the system and the behavior of each node are ignored. (2). The principle of how ZigBee WSN or AI computing can help solve practical problems is not thoroughly explained in the article. (3). The design of the concept has not been validated in practice.

In fact, to solve the above weak points is the first problem we need to solve in our next research: (1). We will continue the research with the experts who specialize in monitoring and control systems to propose the topologies for the integrated system, and to confirm the behavior of each node, that is, what information each node should collect and where to transmit it. If we want to apply ZigBee WSN to underground mines, this problem is the first and the most importance to be solved. (2). There is no doubt that the emergence of AI 
has benefited all walks of life, but the application of AI technology in underground mines is not very mature and perfect, especially in China. Therefore, in this respect, we need to conduct further research and exploration with relevant experts, which is a challenge for us.

Generally speaking, our aim is to solve problem 1 first, and then, we urgently need to test the effect of the locate function of ZigBee WSN in the underground mine. Although a few literature studies [67-70] showed that the ZigBee WSN can be used for underground location, some of them are completely theoretical research, which does not show that ZigBee WSN can have a good application in the underground mines. Therefore, we need do the practical test for the locate function of ZigBee WSN in the underground mine. Our plan is to test the locate function of ZigBee WSN in the ring-shaped transport roadway in the southern section of the $\mathrm{X}$ Mine in our engineering projects, which is a 10-million-ton level mine in China.

If, with the efforts of experts and ours, we carry out a certain degree of the development in the ZigBee WSN and apply it to the location of the underground mines, then we will certainly carry out experimental verification on it at the first time. We believe that whether the results are good or bad can bring some enlightenment to the relevant research.

\section{Discussion and Outlook}

The emergence of driver-less electric vehicles undoubtedly brings opportunities and challenges to all walks of life. Some media [101,102] believe that the emergence of driverless vehicles is clearly an opportunity to facilitate people's future lives and promote the development of the industries, but some researchers $[103,104]$ believe that the emergence of driver-less technology is undoubtedly a challenge at this stage, and many problems are difficult to solve at this stage of science and technology - for example, the variability of traffic flows or the complexity of the transport environment.

Without doubt, the emergence of driver-less vehicles in underground mines is definitely a challenge to current mining technology. In 2016, driver-less technology was better used in subway through the report of Powell et al. [105]. Around 2017, there were reports $[106,107]$ that driver-less technology was going deep into underground mines, which can be seen as a starting point for the application of driver-less technology in underground mines. After 2017, driverless vehicles in underground mines are considered risky and cost-effective. Guo, Du and $\mathrm{Xu}$ [81] optimized the positioning accuracy of driver-less vehicles in underground mines in early 2018, but there are still many defects in operating driver-less vehicles underground. At the time, many people thought driver-less vehicles had encountered bottlenecks in underground mines, but the turnaround also occurred in 2018. Moridi et al. [54,55] published their second study of ZigBee WSN applications in underground mines, which showed that ZigBee WSN could play a greater role in narrow environments such as underground mines. ZigBee WSN, as the medium of information transmission, generally works with GIS (Geographic Information System) to monitor the underground environment condition [54,55]. The GIS system is widely used in underground mines, especially monitoring and alarm; many researchers $[108,109]$ have used the GIS system as a monitoring system in underground mines. As well, the GIS system is also used as the path planning control system for driver-less vehicles on the ground. Zhou et al. [110] and Yu et al. [111] both have used GIS system to route driver-less vehicles. Although the GIS system is widely used, it has some defects in the control of underground driver-less vehicles; therefore, more researchers prefer communication control systems to monitor driver-less vehicles.

Through summing up the successful application of CBTC system in the Las Vegas monorail tram [76], some researchers put forward the application of CBTC system to the monitoring and control of underground driver-less vehicles. Although the CBTC system is generally used in rail transit monitoring and control, they believed that the running environment of driver-less vehicles in underground mines is restricted to the transport lanes which is not as wide as the ground traffic environment, similar to the monorail tram. 
The CBTC system is the traffic control system that is used in various countries at present, so the CBTC system does have a certain advanced in the control of vehicles; especially, the CBTC system can set algorithms in its control system, such as the shortestpath algorithm [92-100] mentioned in the above. The CBTC system, as the monitoring and control system of underground mine transportation, has had a lot of research on it in the past ten years, and there is no doubt that CBTC system will play a more and more important role in the transportation of underground mine in the future.

In addition to the CBTC system, the Volvo Motor Company, Gothenburg, Sweden Sweden [112] began to develop its own monitoring of underground driver-less transport trucks in 2016, and WaveSense, Somerville, MA, USA [113] tried to use Ground-Penetrating Radar in the monitoring of the driver-less transport vehicles, and more and more kinds of sensors appear for the monitoring and control of the driver-less vehicles. The emergence of more and more monitoring systems undoubtedly lays the foundation for the development of driver-less vehicles. No matter what kind of systems or tools will appear, as long as it can be applied to driver-less technology and can solve problems in real life or engineering, researchers who study driver-less technology will not waste their efforts all the time.

Therefore, whether in mining, industrial transportation, or people's lives, if driver-less technology is conquered by researchers as a challenge, it will become an opportunity. If this opportunity can be seized by people, then it will benefit mankind.

\section{Conclusions}

Overall, the type of this paper is a concept paper; similar to an engineering project plan, this paper discusses the possibility of applying the CBTC system and ZigBee WSN to the monitoring and control system of an underground mine, and it reports on the progress in the present stage of some existing research to apply the CBTC system in the driver-less electric transport vehicles in the underground mines.

In the Introduction and Background part, the concept paper sums up the development of the driver-less technology through some relevant literature and news reports and proposes the benefits of the driver-less technology to modern society. More importantly, in this part, the concept paper introduces the background that driver-less technology is moving toward underground mines; thus, the concept paper further explores the advantages of ZigBee WSN and the CBTC system in underground mines for monitoring and controlling. Specifically, at the end of this section, the concept paper leads to its purpose, that is, to summarize the methods based on the CBTC system and ZigBee WSN to solve the practical problems of underground driver-less electric transport vehicle monitoring and control.

In the Idea and Design part, this concept paper briefly summarizes the development process of ZigBee WSN and the CBTC system through some relevant literature, and it summarizes the fundamental reason that both they can be applied to underground driverless technology. According to the idea of Zhang [90], the concept paper combines the functions of ZigBee WSN and CBTC systems into the integrated system.

In the Concept section, this concept paper summarizes the methods of solving practical problems in engineering by referring to the existing literature, especially the proposal of Gao et al. [91] and a few researchers [98-100]. In this part, the Dynamic Fault Tree analysis method [91] is the most important method used in the control system summarized in the relevant literature, it is an accident analysis method that is often used in monitoring systems.

In the work for the next step, we summarize some shortcomings in the design of the integrated system and put forward some future research programs to improve. For this part, we confirm the goal of our next step—-that is, to perfect the ZigBee WSN and verify it in practice.

In the Discussion and Outlook section, the concept paper puts forward the view that the emergence of driver-less technology is both an opportunity and a challenge; if researchers can overcome the challenge, driver-less technology will benefit mankind. This section summarizes the development of the driver-less technology in underground 
mines and puts forward the prospect of driver-less monitoring and control technology in the future.

Finally, the authors claim that the concept paper serves as a guide to the Tossing out a brick to get a jade gem, it has a few implications for the development and the future of the underground mine transportation, and it is hoped that more and more researchers will be interested and engage in the research of this field.

Author Contributions: S.L.-Conceptualization/Resources. G.W.-Writing review and editing/ Visualization. H.Y.-Writing original draft/Writing review and editing/Project administration/ Validation/Supervision. X.W.-Supervision/Validation. All authors have read and agreed to the published version of the manuscript.

Funding: The authors thank the financial supports from the National Natural Science Foundation of China (51804337).

Acknowledgments: Sincere thanks to the leader Haoxuan Yu and his long-term efforts of the whole project. Special thanks to the editors and reviewers for long-term guidance to authors. The authors thank the financial supports from the National Natural Science Foundation of China (51804337).

Conflicts of Interest: The authors declare no conflict of interest.

\section{References}

1. Cheon, S. An Overview of Automated Highway Systems (AHS) and the Social and Institutional Challenges They Face; University of California Transportation Center Working Papers; Springer: Berkeley, CA, USA, 2003.

2. Goto, Y.; Stentz, A. The CMU system for mobile robot navigation. In Proceedings of the 1987 IEEE International Conference on Robotics and Automation, Raleigh, NC, USA, 31 March-3 April 1987; IEEE: Montreal, QC, Canada, 1987 ; pp. 99-105.

3. Goto, Y.; Stentz, A. Mobile Robot Navigation: The CMU System. IEEE Expert 1987, 2, 44-54. [CrossRef]

4. $\quad$ Parker, A.; Thomas, D.; Siewiorek, D.; Barbacci, M.; Hafer, L. The CMU Design Automation System: An Example of Automated Data Path Design. In Twenty-five years of electronic design automation; Association for Computing Machinery: New York, NY, USA, 1988; pp. 531-538. [CrossRef]

5. Stouffer, R. Happy Motoring?: CMU Developing New Propulsion System. Pittsburgh Bus. Times-J. $1989,8,1$.

6. Carley, L.; Garrod, D.; Harjani, R.; Kelly, J.; Lim, T.; Ochotta, E.; Rutenbar, R. ACACIA: The CMU analog design system. In Proceedings of the 1989 IEEE Custom Integrated Circuits Conference, San Diego, CA, USA, 15-18 May 1989; pp. 4.3/1-4.3/5.

7. Anonymous. SICK laser sensors guide driverless vehicles. Mater. Handl. Manag. 2005, 60, 9.

8. Zhang, T.; Liu, X.; Mei, T.; Tang, G.; Li, B.; Wang, X. A novel platform for simulation and evaluation of intelligent behavior of driverless vehicle. In Proceedings of the 2008 IEEE International Conference on Vehicular Electronics and Safety, Blackwell Inn, OI, USA, 22-24 September 2008; pp. 237-240.

9. Womack, B. Google Unveils Driverless Vehicle Prototypes. Mint (New Delhi, India), 28 May 2014.

10. Anonymous. The other driverless VEHICLE: Trials of autonomous cars by Uber and Waymo are grabbing the headlines, but this kind of technology also promises to transform industrial machinery. Eng. Des. 2020, 46, 20.

11. Anonymous. Waymo Plans to Offer Completely Driverless Vehicles. Auto Business News, 11 October 2019.

12. Leggett, D. Ford and Baidu Announce Joint Autonomous Vehicle Testing. Just-Auto.Com, 2 November 2018.

13. Legacy, C.; Ashmore, D.; Scheurer, J.; Stone, J.; Curtis, C. Planning the driverless city. Transp. Rev. 2019, 39, 84-102. [CrossRef]

14. Levy, A. Go green, go driverless. Nature (London) 2015. [CrossRef]

15. McGee, P. Driverless Car Groups Look Past the Engineering Challenge. Financial Time, 24 November 2019.

16. Anonymous. DRIVERLESS. States News Service, 14 March 2019.

17. Anonymous. Driverless car coming. Eng. Rev. 2014, 39, 18.

18. Anonymous. Driverless CARRIAGES. Eng. Des. 2020, 46, 20.

19. Salonen, A.; Haavisto, N. Towards Autonomous Transportation. Passengers' Experiences, Perceptions and Feelings in a Driverless Shuttle Bus in Finland. Sustainability 2019, 11, 588. [CrossRef]

20. Anonymous. Could Driverless Cars Improve Life for People with Disabilities? -BYLN- Ashley Halsey III The Washington Post. Daily Herald, 3 December 2017.

21. Blau, M.; Akar, G.; Nasar, J. Driverless vehicles' potential influence on bicyclist facility preferences. Int. J. Sustain. Transp. 2018, 12, 665-674. [CrossRef]

22. Allan, D. Driverless Cars. Herald (Glasgow Scotland), 1 January 2020.

23. Bissell, D.; Birtchnell, T.; Elliott, A.; Hsu, E.L. Autonomous automobilities: The social impacts of driverless vehicles. Curr. Sociol. 2018, 68, 116-134. [CrossRef]

24. Sanguinetti, E.R. Planning for the Driverless Future: As roads dominated by driverless cars become an increasing reality, plaintiff auto attorneys should prepare now for likely changes to their practices and their clients' needs. Trial 2018, 54, 50. 
25. Talley, E.L. Is the Future of Law a Driverless Car? Assessing How the Data Analytics Revolution Will Transform Legal Practice. Ssrn Electron. J. 2017, 174, 183-205. [CrossRef]

26. Forlano, L. Stabilizing/Destabilizing the Driverless City: Speculative Futures and Autonomous Vehicles. Int. J. Commun. (Online) 2019, 13, 2811.

27. Wu, B.; Tang, Y.; Yan, X.; Soares, C.G. Bayesian Network modelling for safety management of electric vehicles transported in RoPax ships. Reliab. Eng. Syst. Saf. 2021, 209, 107466. [CrossRef]

28. Ferrandino, E.; Capillo, A.; Mascioli, F.; Rizzi, A. Nanogrids: A Smart Way to Integrate Public Transportation Electric Vehicles into Smart Grids. In Proceedings of the 12th International Joint Conference on Computational Intelligence-IJCCI 2020, Budapest, Hungary, 2-4 November 2020; Volume 2020, pp. 512-520. [CrossRef]

29. Hoff, E.B.; Sarker, B.R. An overview of path design and dispatching methods for automated guided vehicles. Integr. Manuf. Syst. 1998, 9, 296-307. [CrossRef]

30. Barshick, C.M.; Helms, M.M. Automated guided vehicles drive aluminum manufacturing into the future. Prod. Inventory Manag. J. 2001, 42, 22.

31. Bellamy, D.; Pravica, L. Assessing the impact of driverless haul trucks in Australian surface mining. Resour. Policy 2011, 36, 149-158. [CrossRef]

32. Bartley, R. Trucking Industry, Military Test Driverless Vehicles. Fiercemobileit, 17 June 2014.

33. Ohashi, F.; Kaminishi, K.; Heredia, J.D.F.; Kato, H.; Ogata, T.; Hara, T.; Ota, J. Realization of heavy object transportation by mobile robots using handcarts and outrigger. ROBOMECH J. 2016, 3, 27. [CrossRef]

34. Sakuyama, T.; Heredia, J.D.F.; Ogata, T.; Hara, T.; Ota, J. Object Transportation by Two Mobile Robots with Hand Carts. Int. Sch. Res. Not. 2014, 2014, 1-15. [CrossRef]

35. Brown, E. Driverless Forklifts. NASA Tech. Briefs 2019, 43, A16-A19.

36. Burke, K. Plants become wall-e world; Self-driving vehicles ferry parts around factory floors. Automot. News 2017, 91, 16.

37. Hjalmarsson-Jordanius, A.; Edvardsson, M.; Romell, M.; Isacson, J.; Aldén, C.; Sundin, N. Autonomous Transport: Transforming Logistics through Driverless Intelligent Transportation. Transp. Res. Rec. 2018, 2672, 24-33. [CrossRef]

38. Benter, A.; Antolovich, M.; Moore, W. Determining bulk density of mine rock piles using ground penetrating radar frequency downshift. In Proceedings of the 2011 6th International Workshop on Advanced Ground Penetrating Radar (IWAGPR), Aachen, Germany, 22-24 June 2011; pp. 1-6. [CrossRef]

39. Meech, J.; Parreira, J. An interactive simulation model of human drivers to study autonomous haulage trucks. Procedia Comput. Sci. 2011, 6, 118-123. [CrossRef]

40. Korane, K.J. Drones come down to Earth: Driverless trucks foretell the future of mining. Mach. Des. 2013, 85, 58.

41. Murden, S. Autonomous Vehicles Lead Rio Tinto and BHP Billiton into Cruise Control. Australian Mining, 5 November 2015.

42. Anonymous. Plugging-in for Productivity. Eng. Mining J. (1926) 2016, 217, 52.

43. Shiers, W.; Barnett, C. Automatic for the people: Driverless trucks is a hot topic among manufacturers at the moment, and while some believe it won't be long before drivers are replaced, others are more conservative. Commercial Motor. 2016, $225,38-41$.

44. Cheng, X. Application of SINS/DGPS integrated navigation technology in unmanned mining vehicles. In Proceedings of the IOP Conference Series: Materials Science and Engineering; IOP Publishing: Bristol, UK, 2019; Volume 569, p. 42001.

45. Doran, B.; Lopez, M. Autonomous vehicles and msha. Pit Quarry 2019, 111, 72.

46. Dong, L.; Sun, D.; Han, G.; Li, X.; Hu, Q.; Shu, L. Velocity-Free Localization of Autonomous Driverless Vehicles in Underground Intelligent Mines. IEEE Trans. Veh. Technol. 2020, 69, 9292-9303. [CrossRef]

47. Dash, A.K.; Bhattcharjee, R.; Paul, P.; Tikader, M. Study and Analysis of Accidents Due to Wheeled Trackless Transportation Machinery in Indian Coal Mines-Identification of Gap in Current Investigation System. Procedia Earth Planet. Sci. 2015, 11, 539-547. [CrossRef]

48. Ghaddar, M.; Ben Mabrouk, I.; Nedil, M.; Hettak, K.; Talbi, L. Deterministic Modeling of 5G Millimeter-Wave Communication in an Underground Mine Tunnel. IEEE Access 2019, 7, 116519-116528. [CrossRef]

49. Ma, L. Study on Intelligent Mine Based on the Application of 5G Wireless Communication System. In Proceedings of the IOP Conference Series: Earth and Environmental Science; IOP Publishing: Bristol, UK, 2020; Volume 558, p. 32050.

50. Kulich, J.; Bleibinhaus, F. Fault Detection with Crosshole and Reflection Geo-Radar for Underground Mine Safety. Geosciences 2020, 10, 456. [CrossRef]

51. Hargrave, C.; Munday, L.; Kennedy, G.; De Kock, A. Mine Machine Radar Sensor for Emergency Escape. Resources 2020, 9, 16. [CrossRef]

52. Ikeda, H.; Kawamura, Y.; Tungol, Z.P.; Moridi, M.A. Implementation and Verification of a Wi-Fi Ad Hoc Communication System in an Underground Mine Environment. J. Min. Sci. 2019, 55, 505-514. [CrossRef]

53. Min, C.; Jinhao, Z. The Application of WiFi 6 Technology in Underground Mine. In Proceedings of the IOP Conference Series: Earth and Environmental Science; IOP Publishing: Bristol, UK, 2021; Volume 687, p. 12153.

54. Moridi, M.A.; Kawamuraa, Y.; Sharifzadeha, M.; Chandab, E.K.; Jang, H. An investigation of underground monitoring and communication system based on radio waves attenua-tion using ZigBee. Tunn. Undergr. Space Technol. 2014, 43, 362-369. [CrossRef] 
55. Moridi, M.A.; Sharifzadeh, M.; Kawamura, Y.; Jang, H.D. Development of wireless sensor networks for underground communication and monitoring systems (the cases of underground mine environments). Tunn. Undergr. Space Technol. 2018, 73, 127-138. [CrossRef]

56. Anonymous. Helicomm and Venture Design Services Announced Text Messaging Mobile Communicator. Business Wire, 6 December 2007.

57. Chen, S.; Yao, J.; Wu, Y. Analysis of the Power Consumption for Wireless Sensor Network Node Based on Zigbee. Procedia Eng. 2012, 29, 1994-1998. [CrossRef]

58. Uradzinski, M.; Guo, H.; Liu, X.; Yu, M. Advanced Indoor Positioning Using Zigbee Wireless Technology. Wirel. Pers. Commun. 2017, 97, 6509-6518. [CrossRef]

59. Mohammad, M.; Kawamura, A.; Sharifzadeh, Y.; Chanda, M.; Knox, E.; Markus, W.; Hyongdoo, J.; Hirokazu, O. Development of underground mine monitoring and communication system integrated ZigBee and GIS. Int. J. Min. Sci. Technol. 2015, 25, 811-818.

60. Li-Min, Y.; Anqi, L.; Zheng, S.; Hui, L. Design of Monitoring System for Coal Mine Safety Based on Wireless Sensor Network. In Proceedings of the 2008 IEEE/ASME International Conference on Mechtronic and Embedded Systems and Applications, Beijing, China, 12-15 October 2008; pp. 409-414.

61. Hongjiang, H.; Shuangyou, W. The Application of ARM and ZigBee Technology Wireless Networks in Monitoring Mine Safety System. In Proceedings of the 2008 ISECS International Colloquium on Computing, Communication, Control, and Management, Guangzhou, China, 3-4 August 2008; Volume 2, pp. 430-433. [CrossRef]

62. Pei, Z.; Deng, Z.; Xu, S.; Xu, X. Anchor-Free Localization Method for Mobile Targets in Coal Mine Wireless Sensor Networks. Sensors 2009, 9, 2836-2850. [CrossRef] [PubMed]

63. Chehri, A.; Mouftah, H.; Fortier, P.; Aniss, H. Experimental Testing of IEEE801.15.4/ZigBee Sensor Networks in Confined Area. In Proceedings of the 2010 8th Annual Communication Networks and Services Research Conference, Montreal, QC, Canada, 11-14 May 2010; pp. 244-247.

64. Bian, J. Application of the wireless sensor network based on ZigBee technology in monitoring system for coal mine safety. In Proceedings of the 2010 International Conference on Computer, Mechatronics, Control and Electronic Engineering, Changchun, China, 24-26 August 2010; Volume 5, pp. 204-206.

65. Li, Q.; Zhao, H.; Liu, P. Research on Robot Network Communication System in Underground Coal Mine Based on ZigBee. In Proceedings of the 2010 Third International Symposium on Information Processing, Qingdao, China, 15-17 October 2010; pp. 22-24. [CrossRef]

66. Cao, Z.; Lu, H.; He, Q. Research of underground staff positioning system based on wireless sensor network. In Proceedings of the 2011 International Conference on Computer Science and Service System (CSSS), Nanjing, China, 13 April 2011 ; pp. 600-603.

67. Jiang, W.; Yang, F. Positioning Algorithm of Underground Personnel Based on ZigBee Technology. Appl. Mech. Mater. 2014, 532, 121-125. [CrossRef]

68. Wang, D.H.; Zhang, Q.Q.; Sun, Y.F. Design of Wireless Voice Communication System in Underground Coal Mine Based on ZigBee. Appl. Mech. Mater. 2014, 548-549, 1402-1406. [CrossRef]

69. Liu, Q.; Chu, Y.Q.; Han, X. Research on MCL for Mobile Underground Miner Location System Based on ZigBee. Appl. Mech. Mater. 2015, 713-715, 2325-2328. [CrossRef]

70. Ge, B.; Wang, K.; Han, J.; Zhao, B. Improved RSSI Positioning Algorithm for Coal Mine Underground Locomotive. J. Electr. Comput. Eng. 2015, 2015, 1-8. [CrossRef]

71. Abane, A.; Daoui, M.; Bouzefrane, S.; Muhlethaler, P. NDN-over-ZigBee: A ZigBee support for Named Data Networking. Futur. Gener. Comput. Syst. 2019, 93, 792-798. [CrossRef]

72. Chi, Z.; Li, Y.; Huang, Z.; Sun, H.; Zhu, T. Simultaneous Bi-Directional Communications and Data Forwarding Using a Single ZigBee Data Stream. In Proceedings of the IEEE/ACM Transactions on Networking, Paris, France, 29 April-2 May 2021; pp. 1-13.

73. Shariff, F.; Rahim, N.A.; Hew, W.P. Zigbee-based data acquisition system for online monitoring of grid-connected pho-tovoltaic system. Expert Syst. Appl. 2015, 42, 1730-1742. [CrossRef]

74. Zhu, L.; Li, Y.; Yu, F.R.; Ning, B.; Tang, T.; Wang, X. Cross-Layer Defense Methods for Jamming-Resistant CBTC Systems. IEEE Trans. Intell. Transp. Syst. 2020,1-13. [CrossRef]

75. Wang, H.; Yu, F.R.; Zhu, L.; Tang, T.; Ning, B. Finite-State Markov Modeling of Leaky Waveguide Channels in CommunicationBased Train Control (CBTC) Systems. IEEE Commun. Lett. 2013, 17, 1408-1411. [CrossRef]

76. Bantin, C.; Siu, J. Radio CBTC for the Las Vegas Monorail. Wit Trans. Built Environ. 2005, 77, 9.

77. Bin, N.; Tao, T.; Min, Q.K.; Hai, G.C. CBTC (Communication Based Train Control): System and development. In Geo-Environment and Landscape Evolution III; WIT Press: Southampton, UK, 2006; Volume 88.

78. Wang, H.; Yu, F.R.; Zhu, L.; Tang, T.; Ning, B. Finite-state Markov modeling of tunnel channels in communication-based train control (CBTC) systems. In Proceedings of the 2013 IEEE International Conference on Communications (ICC), Budapest, Hungary, 9-13 June 2013; pp. 5047-5051.

79. Wang, H.; Yu, F.R.; Zhu, L.; Tang, T.; Ning, B. Finite-State Markov Modeling for Wireless Channels in Tunnel CommunicationBased Train Control Systems. In IEEE Trans. Intell. Transp. Syst. 2014, 15, 1083-1090. [CrossRef]

80. Briginshaw, D. Can CBTC cope with complex rail networks? Int. Railw. J. 2014, 54, 2. 
81. Guo, J.; Du, J.; Xu, D. Navigation and Positioning System Applied in Underground Driverless Vehicle Based on IMU. In Proceedings of the 2018 International Conference on Robots \& Intelligent System (ICRIS), Changsha, China, 26-27 May 2018; pp. 13-16.

82. Czaplewski, K.; Wisniewski, Z.; Specht, C.; Wilk, A.; Koc, W.; Karwowski, K.; Skibicki, J.; Dabrowski, P.; Czaplewski, B.; Specht, M.; et al. Application of Least Squares with Conditional Equations Method for Railway Track Inventory Using GNSS Observations. Sensors 2020, 20, 4948. [CrossRef] [PubMed]

83. Chen, J.; Hwang, Y.; Liao, Y.; Ku, Y.; Yu, C. A rail-to-rail ultra-wide bandwidth hybrid supply modulator for 5G applications with envelope tracking techniques. Int. J. Circuit Theory Appl. 2019, 47, 1907-1921. [CrossRef]

84. Jia, X.; Shi, F.; Guan, Y.; Tang, S.; Tong, M. Zigbee-based wireless gas monitoring sensor alarm system in coal mine. IOP Conf. Ser. Earth Environ. Sci. 2020, 446, 22012.

85. Dorthi, K.; Bayyapu, N.; Karra, R.C. Zigbee based Wireless Data Acquisition System for monitoring of partition stability above old underground coal workings. Arab. J. Geosci. 2020, 13, 1-11. [CrossRef]

86. Liu, Z.; Wang, Y.; Zeng, Q.; Yang, Y.; Dai, Z. Research on Optimization Measures of Zigbee Network Connection in an Imitated Mine Fading Channel. Electronics (Basel) 2021, 10, 171.

87. Celaya-Echarri, M.; Azpilicueta, L.; Lopez-Iturri, P.; Picallo, I.; Aguirre, E.; Astrain, J.J.; Villadangos, J.; Falcone, F. Radio Wave Propagation and WSN Deployment in Complex Utility Tunnel Environments. Sensors 2020, 20, 6710. [CrossRef]

88. Blanco, J.; García, A.; Morenas, J.L. Design and Implementation of a Wireless Sensor and Actuator Network to Sup-port the Intelligent Control of Efficient Energy Usage. Sensors (Basel Switzerland) 2018, 18, 1892. [CrossRef]

89. Fraga-Lamas, P.; Fernández-Caramés, T.M.; Castedo, L. Towards the Internet of Smart Trains: A Review on Industrial IoTConnected Railways. Sensors (Basel Switzerland) 2017, 17, 1457. [CrossRef]

90. Zhang, X. Advanced Parabolic Equation-Based Propagation Modeling for Train Communication Systems. Ph.D. Thesis, University of Toronto, Toronto, ON, Canada, 2018.

91. Gao, P.; Liu, C.; Dong, H.; Zheng, W. A Dynamic Fault Tree Based CBTC Onboard ATP System Safety Analysis Method*. In Proceedings of the 2020 IEEE 23rd International Conference on Intelligent Transportation Systems (ITSC), Rhodes, Greece, 20-23 September 2020; pp. 1-7.

92. Terblanche, S.; Bley, A. An improved formulation of the underground mine scheduling optimisation problem when considering selective mining. Orion (Johannesbg. South Afr.) 2015, 31, 1. [CrossRef]

93. Åstrand, M.; Johansson, M.; Greberg, J. Underground mine scheduling modelled as a flow shop: A review of relevant work and future challenges. J. South. Afr. Inst. Min. Metall. 2018, 118, 1265. [CrossRef]

94. Gamache, M.; Grimard, R.; Cohen, P. A shortest-path algorithm for solving the fleet management problem in under-ground mines. Eur. J. Oper. Res. 2005, 166, 497-506. [CrossRef]

95. O'Sullivan, D.; Newman, A. Optimization-based heuristics for underground mine scheduling. Eur. J. Oper. Res. 2015, 241, 248-259. [CrossRef]

96. Manríquez, F.; Pérez, J.; Morales, N. A simulation-Optimization framework for short-term underground mine production scheduling. Optim. Eng. 2020, 21, 939-971. [CrossRef]

97. Yardimci, A.G.; Karpuz, C. Shortest path optimization of haul road design in underground mines using an evolutionary algorithm. Appl. Soft Comput. 2019, 83, 105668. [CrossRef]

98. Nesbitt, P.; Blake, L.R.; Lamas, P.; Goycoolea, M.; Pagnoncelli, B.K.; Newman, A.; Brickey, A. Underground mine scheduling under uncertainty. Eur. J. Oper. Res. 2021. [CrossRef]

99. Fathollahzadeh, K.; Asad, M.W.A.; Mardaneh, E.; Cigla, M. Review of Solution Methodologies for Open Pit Mine Production Scheduling Problem. Int. J. Min. Reclam. Env. 2021, 1-36. [CrossRef]

100. Sotoudeh, F.; Nehring, M.; Kizil, M.; Knights, P. Integrated underground mining and pre-concentration systems; a critical review of technical concepts and developments. Int. J. Min. Reclam. Env. 2021, 35, 153-182. [CrossRef]

101. Wolff, D. Driving on the Cutting Edge of Autonomous Vehicle Tech. MIT News, 25 February 2021.

102. Anonymous. Agree on rulebook for testing, developing autonomous vehicles. Automot. News 2021, 95, 10.

103. Chen, Q.; Xie, Y.; Guo, S.; Bai, J.; Shu, Q. Sensing System of Environmental Perception Technologies for Driverless Vehicle: A Review of State of the Art and Challenges. Sens. Actuators A Phys. 2021, 319, 112566. [CrossRef]

104. Liu, X.; Yan, Y.; Gan, H. Research on pedestrian detection algorithm in driverless urban traffic environment. Matec Web Conf. 2021, 336, 06002. [CrossRef]

105. Powell, J.P.; Fraszczyk, A.; Cheong, C.N.; Yeung, H.K. Potential Benefits and Obstacles of Implementing Driverless Train Operation on the Tyne and Wear Metro: A Simulation Exercise. Urban Rail Transit 2016, 2, 114-127. [CrossRef]

106. Daly, J. Mining Minus the Miners; Forget Cars-The Driverless-Vehicle Revolution Is Happening Deep Underground; (Brief article); The Globe and Mail: Toronto, ON, Canada, 2017; p. 14.

107. Fitzgerald, B. Driverless Trucks Head Deep Underground. The Australian, 3 December 2015; p. 19.

108. Bascompta, M.; Castañón, A.M.; Sanmiquel, L.; Oliva, J. A GIS-based approach: Influence of the ventilation layout to the environmental conditions in an under-ground mine. J. Environ. Manag. 2016, 182, 525-530. [CrossRef]

109. Liu, H.; Mao, S.; Li, M.; Wang, S. A Tightly Coupled GIS and Spatiotemporal Modeling for Methane Emission Simulation in the Underground Coal Mine System. Appl. Sci. 2019, 9, 1931. [CrossRef] 
110. Zhou, K.; Yu, L.; Long, Z.; Mo, S. Local path planning of driverless car navigation based on jump point search method under urban environment. Future Internet 2017, 9, 51. [CrossRef]

111. Yu, L.; Kong, D.; Shao, X.; Yan, X. A Path Planning and Navigation Control System Design for Driverless Electric Bus. IEEE Access 2018, 6, 53960-53975. [CrossRef]

112. Anonymous. Autonomous Volvo Truck Testing in Regular Operations Underground. Just-Auto.Com, 8 September 2016.

113. Stevenson, S.S. WaveSense Uses Ground-Penetrating Radar to Help Driverless Cars See. Xconomy [BLOG], 25 September 2018. 